\title{
An automated temperature-based option for estimating surface activity and refuge use patterns in free-ranging animals
}

\author{
J.R. Davis ，E.N. Taylor，D.F. DeNardo
}

\begin{abstract}
Accurately assessing free ranging animals' patterns of surface activity and refuge use is critical, yet fundamentally challenging for biologists and wildlife managers. We evaluate the accuracy of an automated technique temperature based activity estimation (TBAE) in estimating surface activity and refuge use patterns of two sympatric reptiles, the western diamond backed rattlesnake (Crotalus atrox) and the Gila monster (Heloderma suspectum) in the Sonoran Desert. TBAE derived from a comparison of body temperature to shaded air temperature was effective in estimating the overall percent surface activity for both rattlesnakes (observed surface activity 51.8\%, TBAE estimated surface activity 48.2\%) and Gila monsters (observed 22.3\%, TBAE 24.5\%). There was, however, considerable interspecific difference in the effectiveness of TBAE in predicting surface activity at specific time points; TBAE was far more accurate for Gila monsters than for rattlesnakes ( $96 \%$ vs. $66 \%$ time point specific accuracy, respectively). We assert that, when validated, TBAE can be used to yield concurrent and accurate body temperatures and activity estimates for multiple free ranging animals, particularly in arid environments, which improves our understanding of animal biology and can be used to inform management decisions.
\end{abstract}

Keywords: Atrox; Biotelemetry; Crotalus; Heloderma; Reptile; Suspectum

\section{Introduction}

Understanding animals' refuge use and surface activity patterns is fundamental to understanding the behavior, ecology, and physiology of animals. Refuge use is common in all taxa and obligatory in many species since refugia often provide living, nesting, and socializing locations, protection from predation (Blumstein et al., 2001; Davis and Theimer, 2004; Martin and Lopez, 2000; Polis, 1980), and, perhaps most notably, a significant buffer from challenging environmental conditions including drought (Beck and Jennings, 2003; Bulova, 2002) and both high (Grant and Dunham, 1988; Rezende et al., 2003; Ricklefs and Hainsworth, 1968) and low (Buck and Barnes, 1999; Dorcas and Peterson, 1998; Peterson, 1987) air temperature extremes. These benefits become increasingly valuable in arid environments because aridity is often accompanied by challenging air temperatures making behaviors that 
benefit both water conservation and thermoregulation (e.g., shifting activity from diurnal to nocturnal, decreasing overall surface activity, hibernation/active-season dormancy) essential for survival. The spadefoot toad (Scaphiopus couchi) and desert tortoise (Gopherus agassizii) of the arid American Southwest exemplify the value of refugia by occupying them more than 90\% of the year (McClanahan, 1967; Nagy and Medica, 1986). Despite the comparative challenges outside refugia, surface activity is equally important since survival and reproduction of most terrestrial vertebrates are dependent on surface activity to obtain essential resources (e.g., food, water, mates, solar irradiation).

Biologists use a variety of approaches to study animals' activity patterns including direct observations (Altmann, 1974; Martin and Bateson, 1993), stationary activity monitoring devices including videography (Clark, 2006; Codd et al., 2003) or passive integrated transponder (PIT) reading devices (Gruber, 2004), and even automated biotelemetry and satellite-linked radiotelemetry (Beaupre and Beaupre, 1994; Christian and Weavers, 1996; Cooke et al., 2004; Kerr et al., 2004; Peterson, 1987). Automated data collection provides several advantages over the other sampling methods for many applications by significantly reducing animal disturbance and allowing researchers to record data semi-continuously (i.e., at programmed time intervals) from multiple free-ranging animals, even when the animals are inaccessible (Beaupre and Beaupre, 1994; Christian and Weavers, 1996; Cooke et al., 2004; Peterson, 1987).

The purpose of this study was to evaluate the accuracy of an inexpensive and reliable automated system in estimating the general location (on the surface or in a refuge) of individuals of two species based on a simple comparison between air temperature ( $\left.T_{\text {air }}\right)$ and the animals' body temperatures $\left(T_{\mathrm{b}}\right.$ 's). The general dichotomy that exists in temperate-zone climates between highly fluctuating $T_{\text {air }}$ and milder, more stable temperatures in thermally insulated refugia-like sub-terranean burrows (Bulova, 2002; Rezende et al., 2003; Shenbrot et al., 2002) and water (Grayson and Dorcas, 2004) led us to test the hypothesis that environmental thermal heterogeneity can be used to predict animal surface activity. We predicted that the thermal dichotomy between air and sub-surface temperatures influences the $T_{\mathrm{b}}$ of free-ranging reptiles in a predictable manner such that $T_{\mathrm{b}}$ can be used to distinguish surface activity from refuge occupation. For example, $T_{\text {air }}$ at our Sonoran Desert field site $\left(32^{\circ} 36^{\prime} 09 \mathrm{~N}, 111^{\circ} 07^{\prime} 48 \mathrm{~W}, 850 \mathrm{~m}\right)$ changes more rapidly than subterranean temperature and $T_{\text {air }}$ and subterranean temperatures are almost always considerably different regardless of time of day or distance below or above ground (Fig. 1). Knowledge of similarly distinct thermal dichotomies have been used to infer

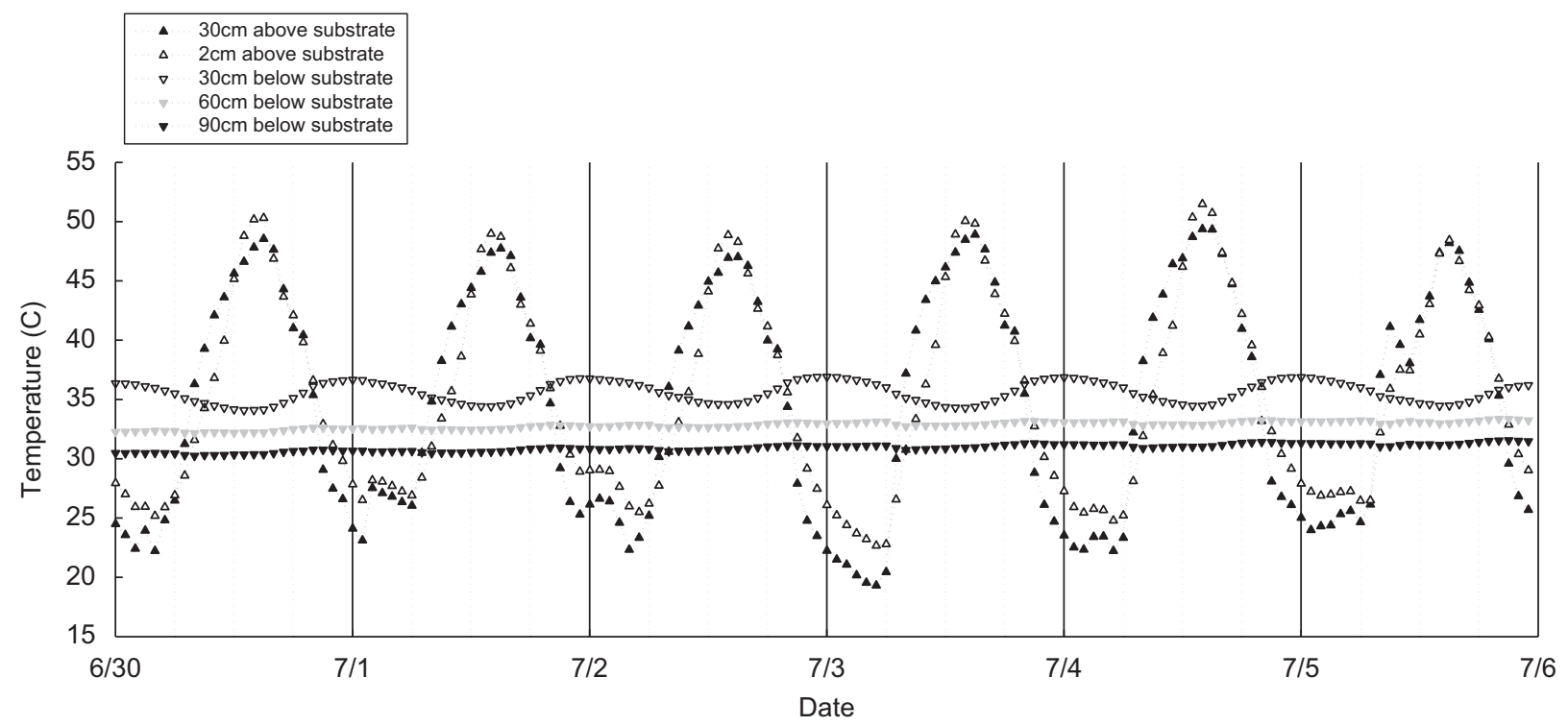

Fig. 1. The dichotomy between air and subterranean temperatures in a temperate zone arid environment. A $5 \mathrm{~d}$ comparison of hourly air and subterranean temperatures at several distances from the surface indicates that, regardless of depth, subterranean temperatures were more stable than were air temperatures and differed from air temperatures in a predictable manner (see text). Dashed vertical lines denote $6 \mathrm{~h}$ intervals and the solid lines indicate $2400 \mathrm{~h}$. 
the location (on surface or in refuge/underwater) of aquatic turtles (Grayson and Dorcas, 2004), snakes (Dorcas and Peterson, 1998; Huey et al., 1989), and lizards (Christian and Weavers, 1996; Kerr et al., 2004); however, the predictive accuracy of such inferences has not been reported. We used a comparison between $T_{\text {air }}$ and individuals' $T_{\mathrm{b}}$ to create temperature-based activity estimations (TBAEs) for each animal studied, and tested our hypothesis by assessing the accuracy of TBAEs by comparing the estimated animal locations (surface or refuge) to time- and date-matched direct observations of radiotelemetered individuals in the field.

\section{Materials and methods}

\subsection{Air temperature and rainfall}

We conducted this study at our long-term field site in the Arizona Upland subdivision of the Sonoran Desert $33 \mathrm{~km}$ NNW of Tucson, Arizona, USA. We recorded rainfall continuously and $T_{\text {air }}$ hourly at the field site before and during the study using an automated rainfall gauge (model RG3-M, Onset Computer, Bourne, MA) and multiple automated temperature loggers (StowAway Tidbit, Onset Computer, Bourne, MA). Data indicate that shaded $T_{\text {air }}$ typically ranges from 5 to $30^{\circ} \mathrm{C}$ in spring and fall (March through mid-May and midSeptember through early November) and from 20 to $45^{\circ} \mathrm{C}$ in summer (mid-May through mid-September). In addition, following unreliable winter rains (November-March), seasonal drought may last 3-4 months before reliable monsoon rains produce $55 \%$ of the annual rainfall $(3$-year annual average $=42 \mathrm{~cm}$ ) from July through mid-September.

Air temperature can vary based on slope, orientation, substrate type, and exposure, and thus is spatially heterogeneous. Therefore, we deployed six temperature loggers to simultaneously record shaded $T_{\text {air }} 1 \mathrm{~m}$ above the ground hourly at six separate locations on our field site. We reduced direct irradiation of the temperature loggers' thermocouple by shading the loggers and suspending each from a tree branch $1 \mathrm{~m}$ above the soil. We recorded $T_{\text {air }}$ on the north and west slopes of two buttes and on the alluvial plains both separating the buttes and also extending to the west of the buttes because field data indicate that many Gila monsters and rattlesnakes spend November-March on the north and west slopes of the buttes and April-October in the adjacent alluvial plains. The thermal profiles among locations were only slightly different. Additionally, $T_{\text {air }}$ recorded at 30 and $2 \mathrm{~cm}$ above the ground also showed substantial similarity (Fig. 1). Based on these findings and for simplicity, we chose to use $T_{\text {air }}$ from one centrally located temperature logger $1 \mathrm{~m}$ above the ground of the alluvial plains between the buttes since data for this study were collected during the active season (April-October). We acknowledge that $T_{\text {air }}$ recorded at a single location does not provide an accurate assessment of all ambient temperatures available to, or $T_{\mathrm{b}}$ 's attainable by, an ectotherm. However, our goal was not to use our $T_{\text {air }}$ data as operative temperature estimates, but instead to simply provide a general reference temperature for comparison with the $T_{b}$ 's of numerous widely dispersed animals. In fact, our intent was to assess whether such a simple estimate of $T_{\text {air }}$ could be used to accurately estimate animal activity, thereby providing a very straightforward and cost-effective way of measuring activity remotely.

\subsection{Study species}

The abilities of many diurnal reptiles to maintain stable $T_{\mathrm{b}}$ (through behavioral thermoregulation, i.e., shuttling) despite significant variation in environmental temperatures have been studied for over six decades (Avery, 1982; Cowles and Bogert, 1944; Peterson, 1987). Many species are neither diurnal nor active behavioral thermoregulators; thus we predicted that for such species $T_{\mathrm{b}}$ tracings would show sufficiently different patterns during activity compared to refuge use to allow animal location (surface active vs. in a refuge) to be accurately discerned. We recorded $T_{\mathrm{b}}$ semi-continuously from a group of western diamondbacked rattlesnakes (Crotalus atrox Baird and Girard) and a sympatric group of Gila monsters (Heloderma suspectum Cope) at the field site. These species are well suited for this study because they are long-lived, large enough (adult mass $=300-700 \mathrm{~g}$ ) to accommodate radiotransmitters and temperature loggers, and easily located using radiotelemetry (Beck, 1990; Taylor et al., 2005). Moreover, neither species typically use active behavioral thermoregulation outside of specific periods (i.e., both bask upon emergence from overwinter dormancy) and both are known to spend substantial time in a variety of refugia and shift predominantly to 
nocturnal surface activity during hot summer months, which simplifies TBAE by eliminating solar irradiation as a heat source (Beck and Jennings, 2003; J. Davis and D. DeNardo, unpublished; Klauber, 1982). Finally, the species represent contrasting foraging modes; rattlesnakes are sit-and-wait predators (Klauber, 1982) and Gila monsters are active foragers (Beck, 2005), which facilitates assessment of TBAE accuracy under these disparate foraging strategies.

\subsection{Body temperatures and field observations}

As part of other studies (Taylor and DeNardo, 2005; Taylor et al., 2005), we used radiotelemetry to locate eight adult female rattlesnakes (mean body mass: 342 $\pm 24.3 \mathrm{~g}$, range: 255-425 g; Table 1) during the 2002 active season (April-October; $n=\mathbf{3 3 0}$ locations). Additionally, we surgically implanted a miniature temperature logger capable of recording 2048 data points (Thermochron iButton, model DS1921G, Maxim Corporation, Dallas, TX, USA) in each rattlesnake. These temperature loggers are small $(<3 \mathrm{~g})$, accurate $\left( \pm 0.5^{\circ} \mathrm{C}\right)$, reliable, inexpensive $(<\mathrm{US} \$ 10)$, and reusable for several years (Angilletta and Krochmal, 2003). Prior to implantation, we programmed the temperature loggers to record $T_{\mathrm{b}}$ every $2 \mathrm{~h}$ from 30 April to 15 October 2002. We collected each rattlesnake from the field in mid-April, surgically implanted a radiotelemeter

Table 1

Individual and species accuracies of temperature based activity estimations (TBAEs) for producing estimates of refuge use and surface activity patterns in free ranging Gila monsters (Heloderma suspectum) and western diamond backed rattlesnakes (Crotalus atrox). TBAE predictions were compared to time and date matched field observations. Proportion correct $=$ mumber of times TBAE correctly identified an animal's location/total number of observations

\begin{tabular}{|c|c|c|c|c|c|c|c|}
\hline \multirow[t]{3}{*}{ Individual } & \multirow[t]{3}{*}{ Body mass } & \multirow[t]{3}{*}{ Sex } & \multicolumn{4}{|c|}{ H. suspectum location } & \multirow[t]{3}{*}{ Proportion correct } \\
\hline & & & \multicolumn{2}{|l|}{ Refuge } & \multicolumn{2}{|l|}{ Surface } & \\
\hline & & & Correct & Incorrect & Correct & Incorrect & \\
\hline G01 & 680 & $\mathrm{~F}$ & 16 & 0 & 0 & 1 & 0.94 \\
\hline G02 & 468 & M & 7 & 0 & 1 & 0 & 1.00 \\
\hline G04 & 642 & M & 5 & 0 & 3 & 1 & 0.89 \\
\hline G08 & 320 & M & 10 & 1 & 3 & 0 & 0.93 \\
\hline G10 & 658 & M & 4 & 0 & 1 & 0 & 1.00 \\
\hline G11 & 485 & M & 7 & 1 & 2 & 0 & 0.90 \\
\hline $\mathrm{G} 23$ & 223 & $\mathrm{~F}$ & 8 & 0 & 2 & 0 & 1.00 \\
\hline $\mathrm{G} 24$ & 231 & M & 10 & 0 & 0 & 0 & 1.00 \\
\hline G25 & 429 & $\mathrm{~F}$ & 5 & 1 & 0 & 0 & 0.83 \\
\hline G26 & 470 & $\mathrm{M}$ & 4 & 1 & 1 & 0 & 0.83 \\
\hline G54 & 341 & M & 12 & 0 & 5 & 0 & 1.00 \\
\hline G55 & 512 & M & 7 & 0 & 5 & 0 & 1.00 \\
\hline G56 & 346 & M & 5 & 1 & 3 & 0 & 0.89 \\
\hline G57 & 610 & $\mathrm{~F}$ & 10 & 0 & 2 & 0 & 1.00 \\
\hline G58 & 347 & M & 10 & 0 & 3 & 0 & 1.00 \\
\hline G59 & 539 & $\mathrm{~F}$ & 19 & 1 & 7 & 0 & 0.96 \\
\hline \multirow[t]{2}{*}{ H. suspectum } & 456.3 & & 139 & 6 & 38 & 2 & 0.96 \\
\hline & & & \multicolumn{4}{|c|}{ C. atrox location } & \\
\hline A5 & 400 & $\mathrm{~F}$ & 19 & 5 & 15 & 6 & 0.76 \\
\hline A19 & 350 & $\mathrm{~F}$ & 16 & 6 & 19 & 7 & 0.73 \\
\hline A 27 & 270 & $\mathrm{~F}$ & 21 & 11 & 10 & 3 & 0.69 \\
\hline A70 & 320 & $\mathrm{~F}$ & 11 & 5 & 12 & 18 & 0.50 \\
\hline A92 & 425 & $\mathrm{~F}$ & 19 & 1 & 12 & 6 & 0.82 \\
\hline A104 & 290 & $\mathrm{~F}$ & 8 & 4 & 13 & 7 & 0.66 \\
\hline A132 & 425 & $\mathrm{~F}$ & 10 & 1 & 9 & 26 & 0.41 \\
\hline A139 & 255 & $\mathrm{~F}$ & 4 & 5 & 18 & 3 & 0.73 \\
\hline C. atrox & 341.9 & & 108 & 38 & 108 & 76 & 0.66 \\
\hline
\end{tabular}


(13g model SI-2, Holohil Systems, Ltd., Carp, Ontario, CA) and temperature logger into the intracoelomic cavity using methods described by Taylor et al., 2004, and released each snake at its site of collection within $48 \mathrm{~h}$, which allowed snakes 2 weeks to recover before temperature loggers began recording data. We used radiotelemetry to locate each rattlesnake 2-6 times per week, during day and night, and we recorded the time and whether the snake was on the surface or in an underground refuge for each encounter. We collected rattlesnakes from the field again in late October, retrieved and downloaded the temperature loggers, and released the rattlesnakes at their site of collection within $48 \mathrm{~h}$.

As part of a separate study (Davis and DeNardo, unpublished), we used radiotelemetry to locate 16 adult Gila monsters ( 5 females, 11 males; mean body mass: $456 \pm 36.6 \mathrm{~g}$; range: $223-680 \mathrm{~g}$; Table 1) $1-5$ times per month between 5 April and 27 August 2003 ( $n=484$ tracking events). As above, we recorded each animal's $T_{\mathrm{b}}$ using the same model temperature logger that we surgically implanted into Gila monsters as described for rattlesnakes (Taylor et al., 2004). Prior to implantation, we programmed 10 temperature loggers to collect $T_{\mathrm{b}}$ hourly (1 April-23 June) and the remaining six to collect $T_{\mathrm{b}}$ every $2 \mathrm{~h}$ starting on 23 April to obtain data from all animals during the mating season (April-May) and less frequent data from some animals through the dry summer (late-May-July) and the monsoon season (August-mid-September). We collected 'hourly' lizards from the field between 13 March and 31 March, surgically implanted the same model radiotelemeter and temperature logger as above and returned the lizards to their site of collection within $48 \mathrm{~h}$. We processed '2-hourly' lizards between 3 April and 12 May in the same manner. We located lizards day and night using radiotelemetry and recorded the time and location (surface or refuge) of each animal. We collected all lizards from the field between 31 August and 4 September, retrieved and downloaded temperature loggers, and returned animals to their site of collection within $48 \mathrm{~h}$.

\subsection{Data analyses}

We compiled a list of dates and times when animals were located using radiotelemetry and noted whether the animal was observed to be on the surface or in a refuge. We refer to the resulting activity data as the 'observed' data. To produce a TBAE for each animal, we synchronized $T_{\text {air }}$ and $T_{\mathrm{b}}$ data temporally and plotted both together on the same graph (Fig. 2a) using SigmaPlot (version 8.0, Systat Software, Point Richmond, CA). Without knowledge of observed results, a single researcher (JRD) then estimated from the graphs (viewed at $400 \%$ ) whether an animal was surface-active or in a refuge at each of the time it was located in the field by applying the following criteria (refer to Fig. 2): (1) surface activity occurred when $T_{\mathrm{b}}$ was similar to $T_{\text {air }}$ in both diel fluctuation and value $\left( \pm 1{ }^{\circ} \mathrm{C}\right.$; we chose this value because it represents two steps in the accuracy of the datalogger recording), (2) refuge use occurred when $T_{\mathrm{b}}$ was distinct from $T_{\mathrm{air}}$ and remained relatively stable over time (at least hours, but often days), (3) a shift from refuge use to surface activity occurred when $T_{\mathrm{b}}$ changed abruptly from a stable temperature and became similar to $T_{\text {air }}$ in both value and fluctuation, (4) basking occurred during daylight hours when $T_{\mathrm{b}}$ was greater than $T_{\text {air }}$, and (5) a shift from surface activity to refuge use occurred when $T_{\mathrm{b}}$ ceased mimicking $T_{\text {air }}$ and became stable over time. These criteria are not absolute. Criterion 2, for example, could underestimate surface activity of animals capable of maintaining $T_{\mathrm{b}}$ distinct from $T_{\text {air }}$ and relatively stable over time as documented in many diurnal reptiles that behaviorally thermoregulate via shuttling (Avery, 1982; Cowles and Bogert, 1944; Huey et al., 1989). Regardless, we determined the overall effectiveness of this set of criteria for predicting surface activity and refuge use by comparing TBAE results to actual observations of free-ranging animals.

We assessed the accuracy of TBAE predictions at each specific time point using Cohen's weighted Kappa test for agreement to assess the predictability of the relationship between observed and estimated activity. Using this statistic, a value of one indicates perfect agreement between observed and TBAE-predicated animal locations and a value of zero indicates that the agreement is no better than chance (Norman and Streiner, 2000). In order to assess the value of TBAE for generating long-term activity estimates in free-ranging reptiles, we calculated the percentage of time Gila monsters and rattlesnakes were surface-active based on three methods: (1) observed surface activity, calculated as observed surface activity divided by total locations $\mathrm{x} 100$ ( $N=484$ for Gila monsters; $N=\mathbf{3 3 0}$ for rattlesnakes), (2) estimated surface activity limited to the observed time points' calculated as above using TBAEs for each tracking event, and (3) estimated surface activity using all recorded data' calculated from each animal's entire TBAE as the number of hours on the surface divided by 

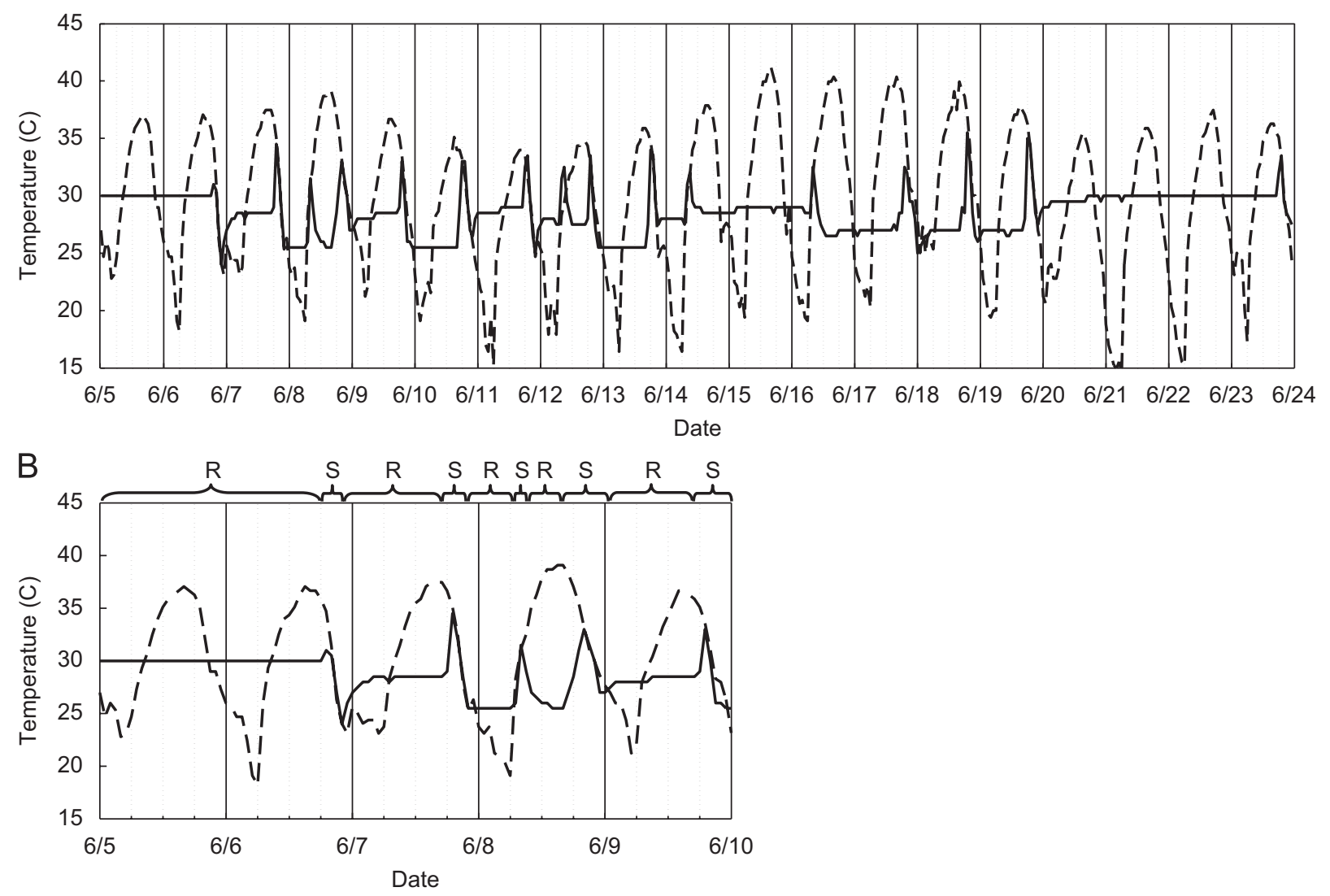

Fig. 2. A sample comparison between Gila monster body temperature ( $T_{\mathrm{b}}$, solid line) and air temperature ( $T_{\text {air }}$, dashed line) used to generate temperature based activity estimation (TBAE). (A) A $19 \mathrm{~d}$ tracing of $T_{\text {air }}$ and $T_{\mathrm{b}}$. Note the extended stable $T_{\mathrm{b}}$ on 56 June and 2023 June, as well as the short periods of stable $T_{\mathrm{b}}$ seen each day indicating both long term and short term refuge use, respectively. (B) An enlargement of the first $5 \mathrm{~d}$ of (A) with brackets above the graph indicating when TBAE predicts the animal to be on the surface (S) or in a refuge (R). Note how, despite the difference in location (animal near the surface vs. $T_{\text {air }}$ measured $1 \mathrm{~m}$ above the surface), the values and diel fluctuations of $T_{\text {air }}$ and $T_{\mathrm{b}}$ during surface activity are very similar. In both plots the dashed vertical lines denote $6 \mathrm{~h}$ intervals and the solid lines indicate $2400 \mathrm{~h}$.

the total hours recorded $\times 100$ ( $T=29919$ time points for Gila monsters; $T=46032$ for rattlesnakes). To address concerns about pseudoreplication, we assessed our results at the individual and species levels. Since body mass affects thermal inertia and thermal inertia could influence the accuracy of TBAE, we used a pairwise correlation to determine whether body mass was related to the accuracy of TBAE in rattlesnakes or Gila monsters $(\alpha=0.05)$. Analyses were performed using SPSS (version 11.0) and JMP IN (version 5.1).

\section{Results}

There was considerable interspecific difference in the accuracy of TBAE. TBAE correctly identified 176 of $184(96 \%)$ Gila monster locations (on surface or in refuge) compared to just 216 of $330(66 \%)$ rattlesnake locations (Table 1). Cohen's weighted Kappa test for agreement indicated that the agreement quality of observations and TBAE for Gila monsters is very good $(\mathrm{Kw}=\theta .88)$ and fair for rattlesnakes $(\mathrm{Kw}=\theta .31)$ meaning that TBAE was much more accurate at each individual time point for Gila monsters than for rattlesnakes. Using TBAE, we correctly predicted surface activity and refuge use more than $95 \%$ of the time for Gila monsters and $62 \%$ and $68 \%$ of the time, respectively, for rattlesnakes (Table 1). Individual variation in TBAE accuracy differed between species, with all lizards being more accurate than all rattlesnakes 
(Table 1), but TBAE accuracy was not significantly correlated with body mass in either species (rattlesnakes, $r=-0.015, p=0.97$; lizards, $r=-0.116, p=0.67$ ). Long-term percent surface activity estimates based on observed surface activity and TBAE limited to observed time points were similar for Gila monsters $(22.3 \%$ and $24.5 \%$, respectively) and rattlesnakes (51.8\% and $48.2 \%$, respectively), showing that TBAE can accurately predict surface activity over the long term in both species. TBAE using all recorded data revealed considerably lower estimated percent activity for both Gila monsters $(17.0 \%$; range $=11.4-22.5 \%$; $T=29919$ time points) and rattlesnakes $(42.5 \%$; range $=21.9-60.4 \% ; T=16032$ time points).

\section{Discussion and conclusions}

Though previous studies have inferred animal location based on temperature comparisons (Christian and Weavers, 1996; Dorcas and Peterson, 1998; Grayson and Dorcas, 2004; Huey et al., 1989), ours is the first to evaluate the accuracy of such inferences based on a comparison of field observations to TBAE. Our results provide partial, species-specific support for the hypothesis that the thermal dichotomy between surface and refuge microenvironments can be used to distinguish surface activity from refuge occupation. This TBAE validation is encouraging for behavioral and ecological studies of Gila monsters, and perhaps other active foraging animals, since TBAE can provide an accurate ( $96 \%$; Table 1), automated, inexpensive, and simple method to assess refuge use and surface activity patterns (not to mention $T_{\mathrm{b}}$ ) of many widely dispersed animals on fine (hourly) and extended (days, months, seasons) temporal scales. The value of TBAE in rattlesnakes is reduced, however, due to lower time-point-specific accuracy, resulting in less accurate estimates during refuge use $(68 \%)$ and surface activity (62\%; Table 1). Generally, our results reiterate the need for empirically derived validations of field techniques, like TBAE, since application of a single method to sympatric species in our study demonstrated clearly different results.

Since the accuracy of TBAE was unrelated to body mass and assessed in both species during the same time of year at the same field site, we attribute the interspecific differences in TBAE accuracy to differences in foraging strategy and consequent microhabitat use of the two species. For instance, during much of the active season Gila monster surface activity is low, predominantly entails foraging for widely dispersed resources (Beck, 1990, 2005), and occurs mostly at night (at our Sonoran Desert field site) when the lack of solar irradiation results in Gila monster $T_{\mathrm{b}}$ 's that closely mimic $T_{\text {air }}$ (Fig. 2b). Between foraging bouts, Gila monsters may remain inactive in a single refuge for several days or weeks, thereby passively maintaining a nearly constant $T_{\mathrm{b}}$ (Fig. 2a). In contrast, the sit-and-wait foraging strategy of western diamond-backed rattlesnakes at our site likely diminished the accuracy of TBAEs since observations revealed that rattlesnakes at our site spend extended periods coiled in well-secluded surface locations (e.g., the base of relatively thick vegetation). These locations are insulated from $T_{\text {air }}$ extremes, resulting in fluctuating rattlesnake $T_{\mathrm{b}}$,s intermediate between $T_{\text {air }}$ and stable subterranean temperatures. Because our criteria could not distinguish amongst the microclimates used by rattlesnakes, there was considerable error in TBAEs for rattlesnakes compared to Gila monsters (Table 1).

By being based on a semi-continuous complete data set, TBAE eliminates many constraints (e.g., time, financial, personnel) and biases (e.g., tracking when convenient for observer or when subject is likely active) (Taylor et al., 2004) that can negatively impact assessments. The negative impact of non-random sampling is illustrated by the difference in TBAE based on the entire data set $(17.0 \%)$ compared to the likely less-accurate estimates resulting from non-random radiotelemetry-based observations $(22.3 \%)$ or TBAE estimates based on these same limited sampling points $(24.5 \%)$. Our estimate that Gila monsters spend $17 \%$ of the active season surface active exceeds other published estimates for Gila monsters based solely on radiotelemetry and field observations. In Arizona, activity estimates range from 2\% to 5\% (Lowe et al., 1986) and extensive work by Beck $(1990,2005)$ suggests $<5 \%$ annual surface activity for Gila monsters in Utah and New Mexico. These differences may be explained by differences in methodology (semi-continuous vs. point-sampling, $24 \mathrm{~h}$ vs. diurnal sampling) or environmental conditions (e.g., the occurrence of late summer monsoon rainfall).

This validation highlights the potential for TBAE in ectothermic species, yet endothermy may not preclude its use since affixing an insulated temperature logger externally to a bird or mammal would yield the temperature of the ambient microenvironment (refuge or surface temperature). Moreover, the small size of the temperature logger $(3 \mathrm{~g})$ and quadrupled memory capacity (Thermochron iButton model DS1922L offers 8kB 
of memory) increase the versatility of TBAE for use in a variety of active foraging species that rely on thermally insulated refugia-like red foxes (Vulpes vulpes), badgers (Meles meles), and cactus wrens (Campylorhynchus brunneicapillus) (Fenn and MacDonald, 1995; Moore and Roper, 2003; Ricklefs and Hainsworth, 1968). Arid environments offer ideal conditions in which to use TBAE since (1) the refugia of resident animals as diverse as arachnids (Polis, 1980; Shillington, 2002), birds (Ricklefs and Hainsworth, 1968), mammals (Jackson et al., 2002; Moore and Roper, 2003; Randall, 1993; Rezende et al., 2003), and reptiles; (Beck and Jennings, 2003; Bradshaw, 1997; Bulova, 2002; Grant and Dunham, 1988) are notably buffered from extreme fluctuations in $T_{\text {air }}$, and thus present the thermal dichotomy required for TBAE and (2) many animals use water-conserving behaviors, including extended inactivity periods and temporally constrained activity (i.e., nocturnality), which improve the accuracy of TBAE (this study). TBAE can also identify the date and time of key annual events such as initiation and cessation of seasonal dormancy (J. Davis and D. DeNardo, unpublished; Nussear et al., 2007) and the $T_{\mathrm{b}}$ data collected for TBAEs provide valuable insight into the thermal biology of the study species (e.g., thermal implications of surface activity, importance of temperature in selecting refugia).

TBAE is an inexpensive, automated technique that can provide fundamental information critical to the management and conservation of species. Although TBAE requires that animals occupy dichotomous thermal microenvironments and it cannot be used to identify the specific type of surface activity occurring (e.g., basking, vigilance, foraging, migration), the method generates otherwise impossible to obtain data (e.g., concurrent hourly activity and $T_{\mathrm{b}}$ patterns of multiple free-ranging animals), and thus can be a valuable tool for assessing the behavioral and thermal ecology of animals. Therefore, TBAE should be considered when designing experiments and if applied, TBAEs should be validated for each application (i.e., species, habitat) using observational data.

\section{Acknowledgments}

We thank M. Malawy for help in the field. This manuscript benefited from reviews by the DeNardo laboratory, the Physiology Reading Group at ASU, G. Walsberg, O. Lourdais, and two anonymous reviewers. This research was funded by the National Science Foundation Graduate Research Fellowships (to JRD and ENT) and private donations to the ASU Foundation. Research was conducted in accordance with Arizona State University's Institutional Animal Care and Use Committee policies (IACUC protocol no. 01-671R). Snakes and lizards were collected under Arizona Game and Fish Department scientific collection permits SP683420 and SP739769 (to JRD and DFD) and SP683705 (to ENT).

\section{References}

Altmann, J., 1974. Observational study of behavior: sampling methods. Behaviour 49, 227267.

Angilletta, M.J., Krochmal, A.R., 2003. The Thermochron a truly miniature temperature logger. Herpetological Review 34 (1), 3132.

Avery, R.A., 1982. Field studies of body temperature and thermoregulation. In: Gans, C., Pough, F.H. (Eds.), Biology of the Reptilia, vol. 12. Physiology C, Physiological Ecology. Academic Press, London, pp. 93166.

Beaupre, S.J., Beaupre, R.W., 1994. An inexpensive data collection system for temperature telemetry. Herpetologica $50,509516$.

Beck, D.D., 1990. Ecology and behavior of the Gila Monster in southwestern Utah. Journal of Herpetology $24,5468$.

Beck, D.D., 2005. Diet, feeding, and foraging ecology. In: The Biology of Gila Monsters and Beaded Lizards. University of California Press, Berkeley, pp. 118131.

Beck, D.D., Jennings, R.D., 2003. Habitat use by Gila Monsters: the importance of shelters. Herpetological Monographs $17,11129$.

Blumstein, D.T., Daniel, J.C., Bryant, A.A., 2001. Anti predator behaviour of Vancouver Island Marmots: using congeners to evaluate abilities of a critically endangered mammal. Ethology 107, 114.

Bradshaw, S.D., 1997. Thermal homeostasis. In: Cloudsley Thompson, J.L. (Ed.), Desert Reptiles. Springer, Berlin, pp. 123161.

Buck, C.L., Barnes, B.M., 1999. Annual cycle of body composition and hibernation in free living arctic ground squirrels. Journal of Mammalogy 80 (2), 430442.

Bulova, S.J., 2002. How temperature, humidity, and burrow selection affect evaporative water loss in desert tortoises. Journal of Thermal Biology 27, 175189.

Christian, K.A., Weavers, B.W., 1996. Thermoregulation of monitor lizards in Australia: an evaluation of methods in thermal biology. Ecological Monographs 66, 139157.

Clark, R.W., 2006. Fixed videography to study predation behavior of an ambush foraging snake, Crotalus horridus. Copeia 2, 181 187. 
Codd, J.R., Sanderson, K.J., Branford, A.J., 2003. Roosting activity budget of the southern bent-wing bat (Miniopterus schreibersii bassanii). Australian Journal of Zoology 51, 307-316.

Cooke, S.J., Hinch, S.G., Wikelski, M., Andrews, R.D., Kuchel, L.J., Wolcott, T.G., Butler, P.J., 2004. Biotelemetry: a mechanistic approach to ecology. Trends in Ecology and Evolution 19, 334-343.

Cowles, R.B., Bogert, C.M., 1944. Preliminary study of the thermal requirements of desert reptiles. Bulletin of the American Museum of Natural History 83, 261-296.

Davis, J.R., Theimer, T.C., 2004. Increased lesser earless lizard (Holbrookia maculata) abundance on Gunnison's Prairie dog colonies and short-term responses to artificial Prairie dog burrows. American Midland Naturalist 150, 282-290.

Dorcas, M.E., Peterson, C.R., 1998. Daily body temperature variation in free-ranging rubber boas. Herpetologica 54, 88-103.

Fenn, M.G.P., MacDonald, D.W., 1995. Use of middens by red foxes: risk reverse rhythms of rats. Journal of Mammalogy 76, $130-136$.

Grant, B.W., Dunham, A.E., 1988. Thermally imposed time constraints on the activity of the desert lizards Sceloperus merriami. Ecology 69, 167-176.

Grayson, K.L., Dorcas, M.E., 2004. Seasonal temperature variation in the painted turtle (Chrysemys picta). Herpetologica 60, 325-336.

Gruber, B., 2004. Measuring activity of geckos with an automatic movement monitoring system. Herpetological Review 35, $245-247$.

Huey, R., Peterson, C.R., Arnold, S.J., Porter, W.P., 1989. Hot rocks and not-so-hot rocks: retreat-site selection by garter snakes and its thermal consequences. Ecology 70, 931-944.

Jackson, T.P., Roper, T.J., Conradt, L., Jackson, M.J., Bennett, N.C., 2002. Alternative refuge strategies and their relation to thermophysiology in two sympatric rodents, Parotomys brantsii and Otomys unisulcatus. Journal of Arid Environments 51, 21-34.

Kerr, G.D., Bull, C.M., Cottrell, G.R., 2004. Use of an on board data logger to determine lizard activity patterns, body temperatures and microhabitat use for extended periods in the field. Wildlife Research 31, 171-176.

Klauber, L.M., 1982. Rattlesnakes, Their Habits, Life Histories, and Influence on Mankind, second ed. University of California Press, Berkeley.

Lowe, C., Schwalbe, C., Johnson, T., 1986. Gila monsters. In: The Venomous Reptiles of Arizona. Arizona Game and Fish Department, Phoenix, Arizona, pp. 11-18.

Martin, J., Lopez, P., 2000. Costs of refuge use affect escape decisions of Iberian rock lizards Lacerta monticola. Ethology 106, 483-492.

Martin, P., Bateson, P., 1993. Measures of behaviour. In: Measuring Behavior. Cambridge University Press, Cambridge, pp. 62-83.

McClanahan, L.L., 1967. Adaptations of the spadefoot toad, Scaphiopus couchi, to desert environments. Comparative and Biochemical Physiology 20, 73-99.

Moore, J.A.H., Roper, T.J., 2003. Temperature and humidity in badger Meles meles setts. Mammal Review 33, $308-313$.

Nagy, K.A., Medica, P.A., 1986. Physiological ecology of desert tortoises in southern Nevada. Herpetologica 42, 73-92.

Norman, G.R., Streiner, D.L., 2000. Measures of association for categorical data. In: Biostatistics. B.C. Decker Inc., Hamilton, Ontario, pp. 217-223.

Nussear, K.E., Esque, T.C., Haines, D.F., Tracy, C.R., 2007. Desert tortoise hibernation: temperatures, timing, and environment. Copeia 2, 378-386.

Peterson, C.R., 1987. Daily variation in the body temperatures of free-ranging garter snakes. Ecology 68, 160-169.

Polis, G.A., 1980. Seasonal patterns and age-specific variation in the surface activity of a population of desert scorpions in relation to environmental factors. Journal of Animal Ecology 49, 1-18.

Randall, J.A., 1993. Behavioral adaptation of desert rodents (Heteromyidae). Animal Behaviour 45, $263-287$.

Rezende, E.L., Cortes, A., Bacigalupe, L.D., Nespolo, R.F., Bozinovic, F., 2003. Ambient temperature limits above-ground activity of the subterranean rodent Spalacopus cyanus. Journal of Arid Environments 55, 63-74.

Ricklefs, R.E., Hainsworth, F.R., 1968. Temperature dependent behavior of the cactus wren. Ecology 49, $227-233$.

Shenbrot, G., Krasnov, B., Khokhlova, I., Demidova, T., Fielden, L., 2002. Habitat-dependent differences in architecture and microclimate of the burrows of Sundevall's jird (Meriones crasses) (Rodentia: Gerbillinae) in the Negev Desert, Israel. Journal of Arid Environments 51, 265-279.

Shillington, C., 2002. Thermal ecology of male tarantulas (Aphonopelma anax) during the mating season. Canadian Journal of Zoology 80, $251-259$

Taylor, E.N., DeNardo, D.F., Malawy, M.A., 2004. A comparison between point- and semi-continuous sampling for assessing body temperature in a free-ranging ectotherm. Journal of Thermal Biology 29, 91-96.

Taylor, E.N., DeNardo, D.F., 2005. Reproductive ecology of western diamond-backed Rattlesnakes (Crotalus atrox) in the Sonoran Desert. Copeia 1, 152-158.

Taylor, E.N., Malawy, M.A., Browning, D.M., Lemar, S.V., DeNardo, D.F., 2005. Effects of food supplementation on the physiological ecology of female western diamond-backed rattlesnakes (Crotalus atrox). Oecologia 144, 206-213. 